ARCHIVO ESPAÑOL DE ARTE, XCI, 364

OCTUBRE-DICIEMBRE 2018, pp. 411-417

ISSN: 0004-0428, eISSN: 1988-8511

https://doi.org/10.3989/aearte.2018.25

\title{
VARIA
}

\section{FRANCISCO PACHECO Y LOS LIBROS PLÚMBEOS DE GRANADA: UN DIBUJO INÉDITO}

\author{
EdUARdo JimÉNEZ FERnÁNDEZ ${ }^{1}$
}

\begin{abstract}
Este trabajo presenta un dibujo inédito atribuido al pintor manierista Francisco Pacheco. Se analiza tanto su técnica como su iconografía y se pone en relación con la cultura de su época, haciendo especial énfasis en la figura del arzobispo Pedro Vaca de Castro y en la secta sevillana de la Congregación de la Granada.

Palabras clave: Francisco Pacheco; dibujo; Libros plúmbeos; Sacromonte; Sevilla; Pedro Vaca de Castro; Congregación de la Granada
\end{abstract}

\section{FRANCISCO PACHECO AND THE "LEAD BOOKS" OF GRANADA: AN UNPUBLISHED DRAWING}

\begin{abstract}
This article presents an unpublished drawing attributed to the Mannerist painter Francisco Pacheco. The author analyzes its technique as well as its iconography and relates it to the culture of the period, stressing the importance of the archbishop Pedro Vaca de Castro and the Sevillian cult of the Congregación de la Granada (Congregation of the Pomegranate).

Key words: Francisco Pacheco; drawing; Lead books; Sacromonte; Seville; Pedro Vaca de Castro; Congregación de la Granada.
\end{abstract}

Cómo citar este artículo / Citation: Jiménez Fernández, Eduardo (2018): "Francisco Pacheco y los libros plúmbeos de Granada: un dibujo inédito". En: Archivo Español de Arte, vol. 91, núm. 364, Madrid, pp. 411-417. https:// doi.org/10.3989/aearte.2018.25.

El hallazgo de los Libros plúmbeos en el Sacromonte granadino es uno de los eventos más relevantes para la vida religiosa en la España de los siglos XVI y XVII. Especialmente, y debido al contenido doctrinal de los mismos, en cuanto está directamente entroncado con las reivindicaciones llevadas a cabo en Sevilla en pro del dogma de la Inmaculada Concepción. Uno de los artistas españoles más preocupados por este dogma fue Francisco Pacheco, quien definió la fórmula iconográfica de la Inmaculada que dominaría gran parte del siglo XVII pictórico.

En razón de las inquietudes religiosas del artista, presentamos un dibujo inédito ${ }^{2}$ (fig. 1) en colección particular que creemos de la mano de Pacheco. Se trata de una escena con varias figu-

\footnotetext{
1 edu.jimenezfernandez@gmail.com / ORCID iD: http://orcid.org/0000-0002-8550-7833.

2 Fue reproducido, pero sin atribución ni estudio, en PRYBRAM-GLADONA, 1969: 85 donde aparece como maestro español de la segunda mitad del siglo XVI. También fue subastado en Christie's Nueva York el 24 de enero de 2001, bajo el lote 86, con una atribución errónea a Romolo Cincinato. Christie's Nueva York 24-I-2001, lote 86.
} 


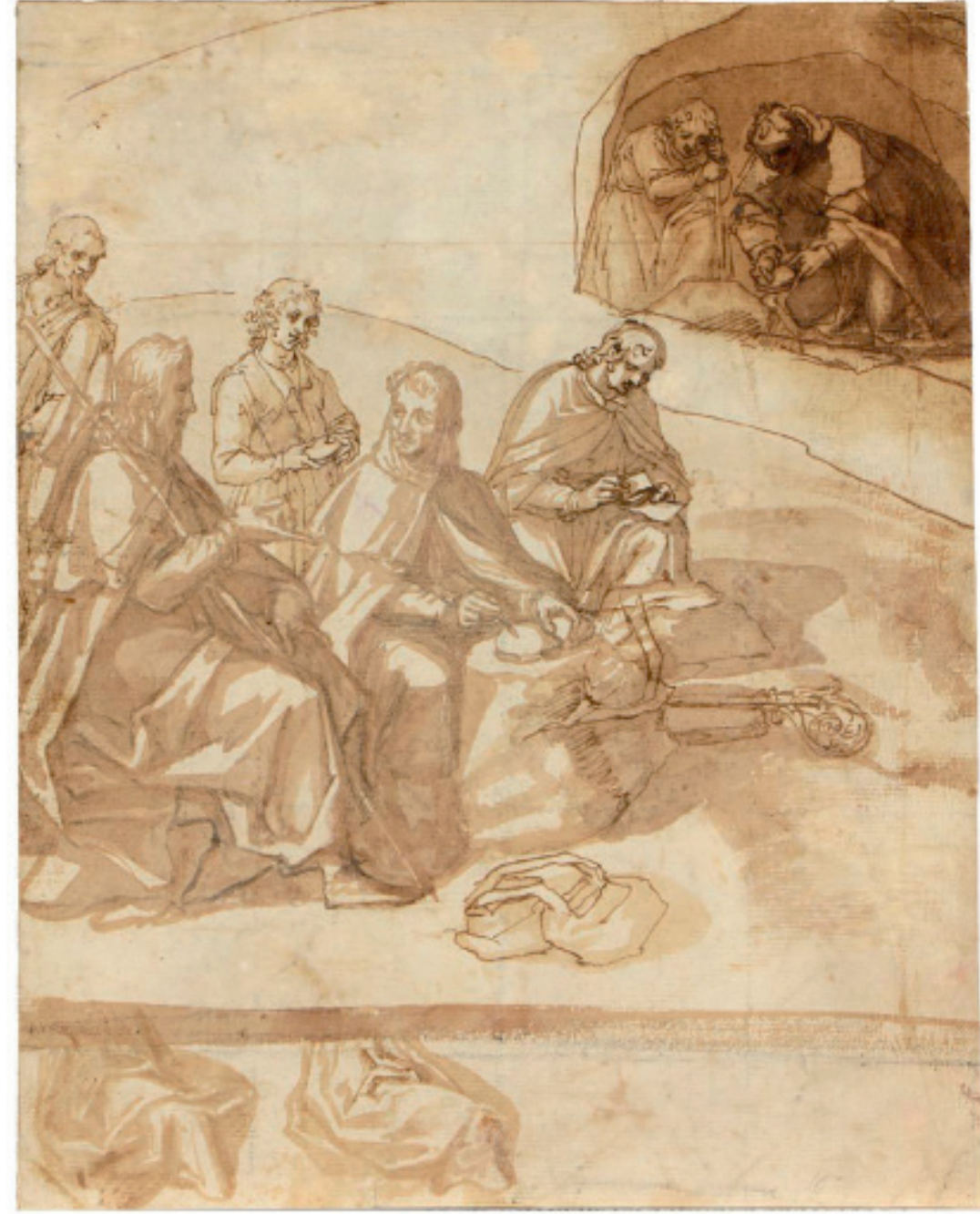

Fig. 1 Francisco Pacheco, Santiago el Mayor dictando a san Cecilio el contenido de los Libros plúmbeos, entre 1610-1623. Pluma, tinta parda y aguada sobre papel verjurado, $297 \times 235$ mm. París, colección particular.

ras sentadas escribiendo mientras, en el último plano, otros personajes entierran o desentierran unos objetos. La composición queda delimitada por debajo con una pincelada de aguada, cortando lo que parece ser el estudio de las piernas de unas figuras sentadas como las de la escena principal o arrodilladas en actitud de adoración. La técnica es la usual de Pacheco en este tipo de obra: pluma, tinta parda y aguada sobre una lámina de papel verjurado de $297 \times 235 \mathrm{~mm}$. En el extremo inferior del papel hay una inscripción que no hemos acertado a leer, acompañada del número 16, que podría ser el inicio de una fecha, práctica habitual para un Pacheco celoso de la autoría de sus obras y riguroso a la hora de fecharlas.

A pesar de que la firma no nos da ninguna pista, el trazo de la pluma es muy cercano a otros dibujos realizados por el pintor, y el análisis de su técnica permite compararlo con otras obras atribuidas con seguridad. Pacheco suele combinar la pluma, la tinta parda y la aguada para dar mayor volumen y detalle a sus obras aprovechando las capacidades expresivas de cada técnica, logrando en ocasiones efectos de gran belleza como en el Ángel de la guarda con un niño (h. 1612-14) conservado en los Uffizi ${ }^{3}$. Sin embargo, en este caso la aguada cobra un mayor

3 Navarrete Prieto, 2016a: 315. 
protagonismo y es el medio por el que quedan representados los dos personajes principales de la escena, en el primer plano. Pacheco se muestra como un maestro de esta técnica con la sutileza de los pliegues del personaje sentado de perfil o con la forma en la que la pierna del personaje sentado de tres cuartos proyecta su sombra sobre la roca.

Típicas en Pacheco son ciertas fisionomías que se ven repetidas en diversas obras y que también podemos encontrar aquí, como es el caso del personaje en el extremo izquierdo, cuyo rostro huesudo es similar al de varios de los santos que aparecen en el registro superior del Juicio Final (1617) de la colección Juan Abellós. La figura en el centro del primer grupo también tiene un aire familiar ya que su rostro recuerda a los tipos que Pacheco solía utilizar en sus ángeles, siendo un ejemplo pintado el ángel que sostiene los lirios en la Inmaculada Concepción (1624) de la iglesia de San Lorenzo de Sevilla. Por otro lado, tanto las pequeñas "c" con las que dibuja su cabello como las líneas quebradas que esbozan sus vestimentas forman parte de su vocabulario formal más corriente, encontrándolas en dibujos como el Proyecto para un retablo: La virgen de la Estrella con Dios Padre, santos y donantes (h. 1595) de la colección Apelles o La Adoración de los pastores de los Uffizi (1607) ${ }^{5}$. La gran semejanza entre dibujos de distintas épocas nos indica hasta qué punto su estilo apenas experimentó una evolución significativa a lo largo de los años, siguiendo una técnica aprendida en el siglo $\mathrm{XVI}^{6}$ : la pluma y la aguada sepia sobre papel, que para él goza de gran reputación al ser la utilizada por Rafael ${ }^{7}$.

El dibujo nos proporciona cuatro claves iconográficas para entenderlo: el personaje central está escribiendo en una suerte de disco, a sus pies hay una mitra de obispo y un báculo pastoral, a su lado hay un personaje que parece dictarle algo y al fondo hay una cueva. Estos elementos en conjunto nos llevan a identificar la escena como la redacción de los Libros plúmbeos que, según se puede leer en ellos, fueron supuestamente escritos en su mayor parte por san Cecilio ${ }^{8}$, primer obispo de Granada, siguiendo el dictado del apóstol Santiago9. La cueva que se ve al fondo evoca una de las cuevas del monte Valparaíso, actual Sacromonte, donde fueron hallados a partir de 1595 los libros junto a las supuestas reliquias de varios santos mártires. Estamos, por tanto, ante un dibujo que representa a Santiago el Mayor dictando a san Cecilio el contenido de los Libros plúmbeos.

Los Libros plúmbeos han sido estudiados como uno de los casos de falsificación histórica más enigmáticos de la historia de España ${ }^{10}$. Son una suerte de faro que arroja luz sobre varios aspectos de la vida religiosa, social y política de la España de cambio de siglo, la que fue testigo de la expulsión de los moriscos entre 1609 y 1611. Creados probablemente con la intención de mejorar la opinión pública que se tenía de los moriscos, estos libros trataron de propiciar un atisbo de permisividad con los residuos del criptoislamismo y evitar una potencial expulsión ${ }^{11}$. Esto explicaría el contenido de los mismos: se trata de una serie de textos doctrinales que com-

\footnotetext{
${ }^{4}$ Navarrete Prieto/Pérez Sánchez, 2009: 56-59.

5 Estos dos dibujos también aparecen relacionados estilísticamente en Véliz, 2002: 137, donde se da a conocer el primero.

${ }^{6}$ Pérez Sánchez, 1986: 176.

7 Pacheco, 1990: 349.

8 San Cecilio y san Tesifón eran, según los libros, dos hermanos árabes llamados Aben al-Radi y Aben Attar (L. Hecker, 2006: 341) que fueron curados por Cristo. Se convirtieron en discípulos del apóstol Santiago y le acompañaron en su misión de evangelizar España. Llegados a Illípula, ciudad supuestamente situada donde se hallaron los plomos y junto a la cual discurría el río Dauro (Darro), subieron a un monte y ahí permanecieron cuarenta días redactando los libros. Martínez Medina, 2006: 83.

9 Martínez Medina, 2006: 86.

10 En Barrios Aguilera/García-Arenal, 2006 se realiza un estado de la cuestión que deja ver cómo estamos lejos de conocer bien el fenómeno y sus múltiples factores. En Pérez Galdeano, 2014: 117-118 hay un repaso por la literatura dedicada al tema incluyendo las publicaciones posteriores a la obra anteriormente citada.

11 El arzobispo Pedro Vaca de Castro y otros muchos partidarios de la causa sacromontana se opusieron a esta medida. Hagerty, 2007: 50.
} 
binan creencias evangélicas y coránicas ${ }^{12}$. Estas últimas, curiosamente, aportan el elemento que más llamó la atención al por entonces arzobispo de Granada, y después de Sevilla, don Pedro Vaca de Castro y Quiñones: la definición del misterio de la pureza de la Virgen bajo la invocación "A María no tocó el pecado primero"13. Hasta en diez ocasiones se hace referencia en los libros a esta idea ${ }^{14}$, y tanto se habla de su figura que se puede afirmar que la Virgen es la protagonista de estos famosos textos.

Don Pedro Vaca de Castro, al igual que gran parte de la población, era un fervoroso defensor de la pureza de la Virgen, y el contenido de estos libros justificaba sus aspiraciones de convertir su devoción al misterio en dogma de la Iglesia. Al haber sido escritos supuestamente por san Cecilio, el primer obispo de Granada, y dictados por el apóstol Santiago, los plomos del Sacromonte gozarían de la misma autoridad que los textos neotestamentarios ${ }^{15}$. Alineado por sus creencias, Vaca de Castro dedicó todos sus esfuerzos durante los últimos años de su vida a defender la legitimidad de estos hallazgos. Así pues, al ocupar la sede hispalense en 1610, se encontró con un grupo con el cual compartía el fervor por la Inmaculada Concepción y del cual se convertiría en un importante aliado: la Congregación de la Granada.

La Congregación fue investigada por la Inquisición, y gracias a ello podemos conocer sus ideas fundamentales y su organización. Un informe redactado por el dominico fray Domingo Farfán en 1626 nos permite saber que "tienen los de esta Congregación por particular y cierta observancia y como profecía que en definiéndose por de fe el punto de la Concepción de Nuestra Señora, habían de reformar la Iglesia los congregados de la dicha Congregación"16. Y es esta fe en la Inmaculada Concepción en lo que se incardinan los intereses de la Congregación, de los jesuitas y franciscanos, del arzobispo Vaca de Castro y finalmente de Francisco Pacheco. En este contexto, cuando en 1623 se publica un edicto de gracia contra los alumbrados, el inquisidor sevillano Alonso de Hoces escribió: "se acabará de descubrir lo de la Congregación de la Granada, que con tanto cuidado procuró el Arzobispo y sus secuaces esconder"17, lo cual pone de relieve el nexo que mantenían ${ }^{18}$.

Según el informe de Farfán de 1626, esta secta reunía en su seno comunes y particulares ${ }^{19}$. Los comunes eran simpatizantes con los aspectos doctrinales de la misma pero ignorantes de un secreto que su fundador, Gómez de Camacho, había pasado a su sucesor, y que este a su vez había confiado a un reducido grupo llamado "del particular espíritu" 20 . Los documentos inquisitoriales no recogen los nombres de los comunes, pero sí los del particular espíritu, entre los cuales se cuentan religiosos y artistas. La presencia de artistas es significativa. A este respecto Vicente Lleó señala un hecho interesante: el jesuita Luis de Alcázar ${ }^{21}$ declaró en un folleto publicado en 1603 que "por una singular gracia de Dios" había comprendido que la única forma de entender el Apocalipsis era mediante sus imágenes, las cuales habrían de ser traducidas de lo

12 Lleó, 2007: 102. En el prólogo a la segunda edición de Los Libros Plúmbeos del Sacromonte, Hagerty sugiere que el texto árabe original parece revelar una relación más profunda, de carácter simbiótico, entre las comunidades cristianas y moriscas. Así, estos textos podrían ser un fruto natural de esta simbiosis más que una falsificación cuidadosamente orquestada por grupo reducido de personas. Hagerty, 2007: 13-17.

13 Martínez Medina, 2006: 91.

14 Martínez Medina, 2006: 91.

15 Martínez Medina, 2006: 87.

16 Huerga, 1988: 221.

17 Huerga, 1988: 188

18 Vicente Lleó recoge estos y otros testimonios de la época que insisten en esta relación entre las partes. Lleó, 2007.

19 Huerga, 1988: 220

${ }^{20}$ Huerga, 1988: 221

${ }^{21}$ Pacheco reconoce haber seguido sus recomendaciones a la hora de fijar la iconografía de la Inmaculada Concepción en su Arte de la Pintura: "En la luna, especialmente, he seguido la docta opinión de el P. Luis del Alcázar, ilustre hijo de Sevilla, cuyas palabras son estas: 'Suelen los pintores poner la luna a los pies desta mujer, hacia arriba; pero, es evidente entre los doctos mathemáticos, que si el sol y la luna se carean, ambas puntas de la luna han de verse hacia abaxo, de suerte, que la mujer no estaba sobre el cóncavo, sino sobre el convexo"”. Pacheco, 1990: 577. 
retórico a lo visual ${ }^{22}$. De esta manera, en su análisis sobre la Congregación de la Granada, Vicente Lleó ha interpretado este pasaje como una prueba de la importancia que tenía el arte para la secta, destacando a un artista en la lista de los del particular espíritu: el escultor Juan Martínez Montañés, cercano colaborador de Francisco Pacheco.

Como también ha demostrado Lleó ${ }^{23}$, Pacheco se movía en círculos que simpatizaban con la Congregación y, aunque él no fuera un miembro, sí era un convencido defensor del dogma de la Inmaculada Concepción. El maestro de Velázquez realizó numerosas versiones de esta iconografía, varias de las cuales incluyen retratos de miembros de la Congregación en actitud orante, y colaboró en la policromía de algunas de las esculturas más importantes, como la Inmaculada de la catedral de Sevilla realizada por Martínez Montañés entre 1629-1631. Sin embargo, no encontramos referencias en su Arte de la Pintura ni en su Libro de Retratos ${ }^{24}$ al arzobispo don Pedro Vaca de Castro, paladín de los libros del Sacromonte. A pesar de esta importante ausencia en los principales escritos de $\mathrm{Pacheco}^{25}$, es difícilmente creíble que el pintor no frecuentara al arzobispo teniendo en cuenta los círculos en los que ambos se movían, siendo además muy improbable que pasara por alto un hallazgo de tal importancia para la cultura de la época.

Al no quedar constancia de la hipotética relación entre el artista y el prelado, no podemos saber si este dibujo fue inicialmente un encargo realizado para ilustrar la Historia Eclesiástica de Granada de Justino Antolínez ${ }^{26}$, cuyos grabados fueron realizados por Francisco Heylan ${ }^{27}$. Algunas de las composiciones estaban basadas en dibujos de Girolamo Lucenti da Correggio ${ }^{28}$, un artista afincado en Sevilla y que había realizado alguna obra importante. Por lo tanto, cabe la posibilidad de que en un primer momento el encargo de proporcionar composiciones recabara en Pacheco, pero que finalmente no fueran del agrado de los comitentes y pasara al pintor italiano. Hubiera colaborado Pacheco o no en esta empresa, entre los grabados realizados por Heylan no hay ninguno que se corresponda con el tema representado en el dibujo que damos a conocer aquí. Finalmente esta obra no vio la luz, y las 28 planchas abiertas por Francisco Heylan entre 1612 hasta 1624 no fueron conocidas más que por un reducido grupo de personas ${ }^{29}$.

Teniendo en cuenta lo que acabamos de apuntar, y sin olvidar su cercanía a la Congregación de la Granada y su interés por el dogma de la Inmaculada Concepción, defendido en los libros, no podemos descartar que este dibujo se trate simplemente de la respuesta de un Pacheco curioso e interesado por los eventos que agitaban la sociedad popular de su momento. De la misma manera que la Sevilla de principios del siglo XVII fue testigo de los movimientos populares en defensa de la Inmaculada Concepción ${ }^{30}$, cuya iconografía tiene una gran presencia en la obra pictórica de Pacheco, en Granada hubo una reacción similar ${ }^{31}$ con el hallazgo en el Sacromonte de las reliquias martiriales de san Cecilio y de sus discípulos. El tipo de dibujo haría plausible esta segunda teoría, ya que sus características, muy esbozado y compartiendo página con otro estudio en la parte inferior, nos hacen sospechar de un ensayo o boceto más espontáneo que de

\footnotetext{
22 Lleó, 2007: 105.
}

23 Lleó, 2007: 107.

24 Sí hay, sin embargo, varias biografías de miembros "del particular espíritu" de la Congregación de la Granada. Gracias a él tenemos más datos sobre dos de las cabezas de la Congregación: Rodrigo Álvarez y Fernando de Mata.

${ }^{25}$ Debido quizás a la prohibición de publicar cualquier cosa referida a los Libros plúmbeos o a su contenido incluida en el breve Dudum cum ex tuae Fraternatis, emitido el 1 de julio de 1598, precedido además por otros dos de 1596 y 1597. Martínez Medina, 2000: 635. Entre 1639 y 1641, los años previos a la publicación del Arte de la Pintura, tanto el Santo Oficio como Roma insisten en la prohibición de cualquier manuscrito o impreso que tratara sobre los Libros plúmbeos. Hagerty, 2007: 52-53.

26 Él fue la mano derecha del arzobispo Pedro Vaca de Castro cuando estaba en Granada y fue quien encargó a Heylan los grabados para ilustrar la Historia Eclesiástica de Granada. Pérez Galdeano, 2014: 116.

27 Ana María Pérez Galdeano hace un buen estado de la cuestión en Pérez Galdeano, 2014.

28 Sotomayor, 1996: XXXVIII.

29 Pérez Galdeano, 2014: 118.

30 Lleó, 2007: 102-103.

31 Harris, 2007: 5. 
un dibujo preparatorio como el del Juicio Final (1610-1614) del Museo del Prado ${ }^{32}$ o el de la Apoteosis de Hércules (1604) conservado en el Museo de la Academia de Bellas Artes de San Fernando $^{33}$. Por el contrario, en estos últimos se aprecia un carácter de obra casi final, con una técnica preciosista y limpia, lo que se opone en este Santiago el Mayor dictando a san Cecilio el contenido de los Libros plúmbeos a un uso desigual de la pluma y la aguada. A la luz de todo lo que hemos dicho, y teniendo presente la homogeneidad del estilo de Pacheco a lo largo de su vida, podríamos proponer una datación para el dibujo entre 1610, año en que el arzobispo Vaca de Castro llega a Sevilla, y 1623, año de su muerte. Sería extraña una fecha más tardía ya que el número de personas que cuestionaba la legitimidad de los Libros plúmbeos crecía año tras año ${ }^{34}$.

Volvamos por un momento a la motivación que podría haber llevado a Pacheco a realizar este dibujo que nunca se concretó, que sepamos, en una pintura al óleo ni en un grabado. Como demuestra el final de su tratado, el Arte de la Pintura, editado en 1649, le preocupaba la corrección iconográfica y el decoro en las pinturas sagradas ${ }^{35}$. Pacheco debía creer en la autenticidad de los Libros y el tema le resultaría lo suficientemente relevante como para ensayar y proponer un prototipo iconográfico mediante un modelo de representación que podría aspirar a convertirse en el habitual o en el aconsejable. Santiago el Mayor dictando a san Cecilio el contenido de los Libros plúmbeos es un tema que carece, como hemos visto, de tradición iconográfica, y Pacheco podría haber tomado la oportunidad para crearla. Esto sería tanto más interesante para un artista que solía justificar ciertas decisiones artísticas apelando a ejemplos más antiguos que actúan como garante ${ }^{36}$. Como dice Bassegoda, quien ha estudiado en profundidad la teoría de Pacheco, las opiniones del pintor son propuestas para el debate intelectual y no son leyes refrendadas por la autoridad de la Iglesia ${ }^{37}$. Así, el hecho de que se decidiera a escribir este ensayo es sintomático del tipo de artista que era, o que al menos se consideraba a sí mismo: un artista intelectual, uno situado en el rango más alto al ser capaz de inventar composiciones en lugar de copiar obras de otros artistas. En efecto, el primer capítulo del tercer libro del Arte está consagrado a los "rasguños, debuxos y cartones y de las varias maneras de usarlo" 38 , donde pasa a describir los estudios preparatorios, dibujos y cartones de los que se sirven los pintores que están en el tercer grado $^{39}$, el más alto, de la pintura. En este tercer grado, y a diferencia de los otros dos, prevalece la invención en lugar de la copia de fórmulas ${ }^{40}$, e insiste en que estos pintores perfetos "procuran enterarse de cómo se ha de pintar, o por información de sabios, o por leción [sic] de libros y en su idea fabrican un todo" 41 . En conclusión, es desde esta óptica desde la que se podría intentar entender este dibujo, el cual aúna creación artística y comprensión intelectual del tema a representar con el interés añadido de aspirar a establecerse como modelo a seguir por otros pintores.

No sería sorprendente que Francisco Pacheco fuese un común de la Congregación de la Granada teniendo en cuenta sus amistades, sus inquietudes espirituales, sus intereses y las obras de arte que llevó a cabo. La iconografía del dibujo que hemos descubierto es clara, puesto que son muchos los símbolos asociados a la historia de los Libros plúmbeos, y la técnica es realmente cercana a la habitual en Pacheco. A pesar de todo, no tenemos ninguna prueba concluyente que certifique esta afiliación con la Congregación o un contacto cercano con el arzobispo don Pedro Vaca de Castro, ya que por lo demás en su Arte de la Pintura no hace ninguna refe-

32 Navarre Prieto, 2010.

33 Jiménez Fernández, 2015: 96-97.

34 Hagerty, 2007: 51-52.

35 Dividido en tres libros, añade un cuarto titulado: “Adiciones a algunas Imágines" en el que, utilizando su propia experiencia y apelando a diversos intelectuales, da recomendaciones sobre la forma más correcta de representar ciertos temas sagrados.

${ }^{36}$ Navarrete Prieto, 2016b: 73.

37 Bassegoda, 2016: 38.

38 Pacheco, 1990: 433.

39 La descripción de los tres grados de pintores la hace Pacheco en el capítulo XII del primer libro, "De tres estados de pintores, que comienzan, median y llegan al fin". Pacheco, 1990: 265-276.

40 Pacheco, 1990: 435.

41 Pacheco, 1990: 435 
rencia a los Libros plúmbeos del Sacromonte de Granada ni a los santos que protagonizan su redacción. En cualquier caso, este nuevo dibujo, que enriquece el corpus de obra gráfica de Pacheco aportando un nuevo matiz hasta ahora insospechado, refleja las preocupaciones de un artista consciente de las novedades religiosas de su tiempo, y empeñado en aportar nuevos modelos artísticos en una época en la que cristalizan los principales emblemas visuales del arte español del Siglo de Oro.

\section{BIBLIOGRAFÍA}

Barrios Aguilera, Manuel/García-Arenal, Mercedes (2006): Los Plomos del Sacromonte. Invención y tesoro. Zaragoza: Universidad de Zaragoza

Bassegoda i Hugas, Bonaventura (2016): “Algunas precisiones sobre Francisco Pacheco y la iconografía sagrada”. En: Pacheco: Teórico, artista, maestro (1564-1644). Sevilla: Junta de Andalucía, Consejería de Cultura, pp. 37-47.

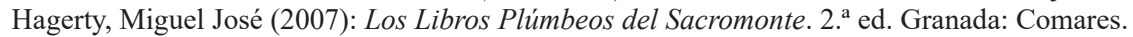

Harris, A. Katie (2007): From Muslim to Christian Granada: inventing a city's past in early modern Spain. Baltimore: John Hopkins University Press.

Huerga, Álvaro (1988): Historia de los alumbrados. Vol. IV. Los alumbrados de Sevilla (1605-1630). Madrid: Fundación Universitaria Española.

Jiménez Fernández, Eduardo (2015): “Francisco Pacheco (1564-1644). Dessin préparatoire pour L'Apothéose d'Hercule". En: Velázquez. París: Grand Palais, pp. 96-97.

L. Hecker, Heather (2006): "Piedras árabes: Rodrigo Caro y su traducción de las inscripciones árabes de Sevilla (1634)". En: Barrios Aguilera, Manuel/García-Arenal, Mercedes (eds.): Los Plomos del Sacromonte. Invención y tesoro. Zaragoza: Universidad de Zaragoza, pp. 335-384.

Lleó, Vicente (2007): “La Sevilla del Siglo de Oro: ortodoxias y heterodoxias”. En: Portús Pérez, Javier (ed.): Fábulas de Velázquez. Madrid: Museo Nacional del Prado, pp. 95-112.

Martínez Medina, Francisco Javier (2000): "Los libros plúmbeos del Sacromonte de Granada". En: Martínez Medina, Francisco Javier (ed.): Jesucristo y el emperador cristiano. Córdoba: Obra social y cultural Cajasur, pp. 619-643.

Martínez Medina, Francisco Javier (2006): "Los hallazgos del Sacromonte a la luz de la Historia de la Iglesia y de la Teología católica”. En: Barrios Aguilera, Manuel/García-Arenal, Mercedes (eds.): Los Plomos del Sacromonte. Invención y tesoro. Zaragoza: Universidad de Zaragoza, pp. 79-111.

Navarrete Prieto, Benito (2010): “A New Preparatory Drawing for Francisco Pacheco's Last Judgement: Creative Process and Theological Approval”. En: Master Drawings, 48, 4. Nueva York: Master Drawings Association, pp. 435-446.

Navarrete Prieto, Benito (2016a): I segni nel tempo. Dibujos españoles de los Uffizi. Madrid: Fundación Mapfre.

Navarrete Prieto, Benito (2016b): "El dibujo como fundamento del pensamiento de Francisco Pacheco: procesos y principios". En: Pacheco: Teórico, artista, maestro (1564-1644). Sevilla: Junta de Andalucía, Consejería de Cultura, pp. 69-83.

Navarrete Prieto, Benito/Pérez Sánchez, Alfonso E., colaboración Roberto Alonso Moral(2009): Álbum Alcubierre: dibujos: de la Sevilla ilustrada del Conde del Águila a la colección Juan Abelló. Madrid: Fundación Arte Hispánico.

Old Master Drawings, Nueva York, Christie's, 24 de enero de 2001.

Pacheco, Francisco (1990): El Arte de la Pintura. ed. Bassegoda, Bonaventura. Madrid: Cátedra.

Pérez Galdeano, Ana María (2014): "Francisco Heylan. Revisión biográfica del calcógrafo e impresor flamenco asentado en Andalucía". En: Anales de Historia del Arte, 24, Madrid: Ediciones Complutense, pp. 107-133.

Pérez Sánchez, Alfonso E. (1986): Historia del dibujo en España: De la Edad Media a Goya. Madrid: Cátedra.

Prybram-Gladona, Charlotte von (1969): Unbekannte Zeichnungen alter Meister aus europäischem Privatbesitz. Munich: Prestel-Verlag.

Sotomayor, Manuel (1996): "Introducción”. En: Antolínez de Burgos, Justino: Historia Eclesiástica de Granada. Introducción, edición, notas e índices por Manuel Sotomayor. Granada: Servicio de Publicaciones de la Universidad de Granada.

Véliz, Zahira (2002): Dibujos españoles del Siglo de Oro: The Apelles Collection. Oviedo: Museo de Bellas Artes de Asturias.

Fecha de recepción: 19-X-2017

Fecha de aceptación: 16-I-2018 